\title{
A Computerized Model for Lean Performance Measurement
}

\author{
Wai Peng Wong, Member IACSIT
}

\begin{abstract}
Lean manufacturing had been engraved in the heart of manufacturing practices as one of the corporate strategy to bring the organization to the forefront of business excellence. Organizations are striving to be lean in order to remain globally competitive. From the lens of lean transformation, organizations aim to achieve leanness in their operations and therefore it is important for them to measure lean performance. This paper develops a computerized model based on Analytical Network Process (ANP) to measure lean performance. The results indicated the computerized model for lean performance system is very beneficial for the company. The model has managed to strengthen the team work in the organization which is an important element in a lean system.
\end{abstract}

Index Terms-Computer model, lean, performance, ANP.

\section{INTRODUCTION}

In lean, company focuses on producing high quality products in the most efficient and economical way possible while incorporating less human effort, less inventory, less time to develop products, and less space to become highly responsive to customer demands [1]. By cutting down unnecessary wastes in all resources, organizations will have more reserves of these resources to be used in future, thus, sustainability can be prolonged. Companies such as Honda, Toyota and many other corporations had successfully sustained their performance through the lean approach [2].

Despite successful "lean" applications in most organizations, the journey to implement lean is not an easy one and is bound to encounter various challenges. One common challenges is the difficulty in assessing lean performance [3] - [4]. This paper aims to develop a computer model to assess lean performance. In this model, a unified index using Analytic Network Process (ANP) technique will be estimated to represent lean performance. The rest of this paper will be organized as follows. In Section II, the development of the model will be illustrated. In Section III, application of the model will be discussed and results presented Section IV concludes the paper.

\section{Model DeVELOPMENT}

ANP is chosen as the method in this research because it can handle complex relationships among the decision levels and the lean attributes. The interaction or interrelationship can be controlled through the coupling of phases that comprise the hierarchies of criterias and sub-criterias. By

Manuscript received July 15, 2013; revised November 1, 2013.

Wai Peng Wong is with the School of Management, Universiti Sains Malaysia, 11800 Penang, Malaysia. (e-mail: wongwp@usm.my). using ANP, the integrated leanness index can be synthesized through the weighted priority of the control criterions through the evaluation of the super-matrices in ANP.

The operations in ANP can be briefly described as follows: in the $1^{\text {st }}$ phase, it consists of control hierarchy of network of criteria and sub-criteria that control the interactions; in the $2^{\text {nd }}$ phase, it consists of network of influences among the elements and clusters, (note: network varies from criteria to criteria), and hence in here also, different super-matrices of limiting influences are computed for each control criteria and finally each one of these super-matrices is weighted by the priority of its control criteria and results are synthesized through addition for the entire control criterion.

To develop the index, first, we need to understand what are the metrics that the organization used. As predicted, different departments in the organization have their own sets of performance metrics and these metrics are not aligned with each other. For instance, the main emphasis of the quality assurance department is quality where else, production and planning department focused mostly on on-time delivery to the customers, while purchasing department emphasized on lowest cost.

Table I shows the common indicators used in the organization that implement lean. And we match them to the ANP structure.

TABLE I: MATCHING OF ORGANIZATION INDICATORS TO ANP STRUCTURE

\begin{tabular}{llll}
\hline \hline 1st level & 2nd level & 3rd level & 4th level \\
\hline Goal & Criteria & Sub-criteria & $\begin{array}{l}\text { Further } \\
\text { Sub-criteria }\end{array}$ \\
Unified & Performance & Performance & Performance \\
index & determinants & dimensions & enablers \\
& - cost & - corporate \& & - leadership, \\
& - quality & intra-organization & employees \\
& - on & alignment & work attitude, \\
time-delivery & - projects and & communication. \\
& information & - improvement \\
& technology & projects (5S), \\
& & -planning control accuracy, & information \\
& and execution & exchange. \\
& & -resource & -workers, \\
& capability & machines and \\
& & materials \\
& & scheduling. \\
& & -labour skill, \\
& & machine \\
& & condition and \\
& & materials \\
& & & quality. \\
\hline \hline
\end{tabular}

The detail steps in ANP procedures are as follows: Step 1: Model construction and problem structuring Step 2: Pair-wise comparison matrices between 
component/attribute levels

Step 3: Pair-wise comparison matrices of interdependencies

Step 4: Super matrix formation and analysis

Step 5: Calculation of the leanness index.

Using the ANP Procedures, i.e., pair-wise comparisons and supermatrix formation, the unified index eventually can be calculated [5]. The unified index, Lindex is calculated as the product of integrated weight with the relative importance of the performance determinants $\left(C_{a}\right)$ i.e.,

$$
\boldsymbol{L}_{\text {index }}=\boldsymbol{W}^{\prime} \times C_{a}
$$

To facilitate the estimation of the unified index, a computerized software program was developed. This program serves to obtain the required inputs i.e., the pair-wise comparisons from the managers and has embedded with the underlying mathematical formulas to estimate the index. This program enables managers to provide their inputs easily through a user-friendly graphical interface.

\section{A. Program for the ANP network}

This section gives an overview of the lean ANP program. The snapshots of the program with its brief illustration are shown below.

\section{B. Main Page}

This is an introduction page to briefly introduce the application and provide a background of Analytical Network Process (ANP) to the users.

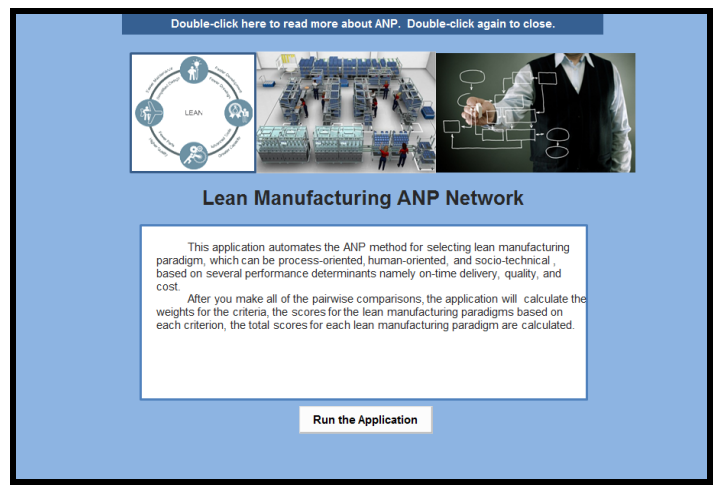

Fig.1. Main page.

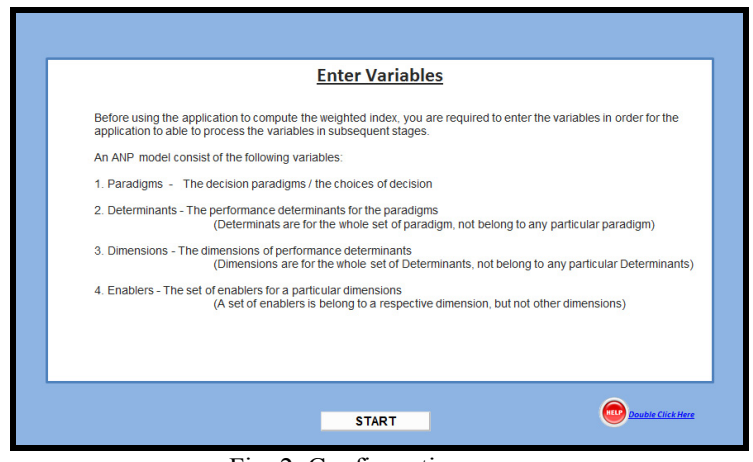

Fig. 2. Configuration page.

\section{Configuration Page}

This page is where users are informed about what are the inputs required by the application in order to run the analysis.

The following is where user can enter their parameters to be run by the application. Input validation will be executed to ensure all the required fields are filled.

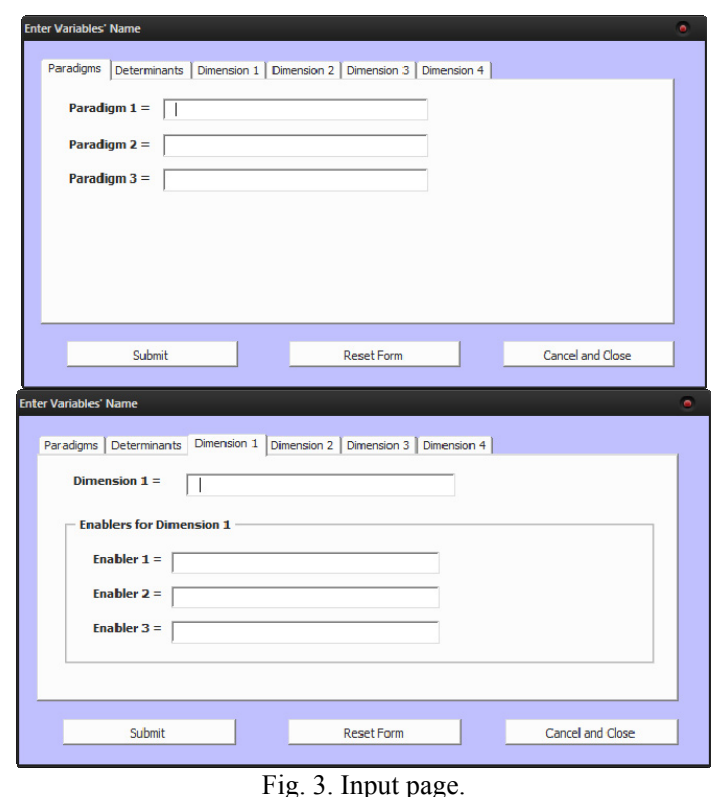

\section{Progress Tracking Page}

This page is where progress is displayed. Most of the information is dynamically generated. The users have the options to "redo the previous section" or proceed to the next section.

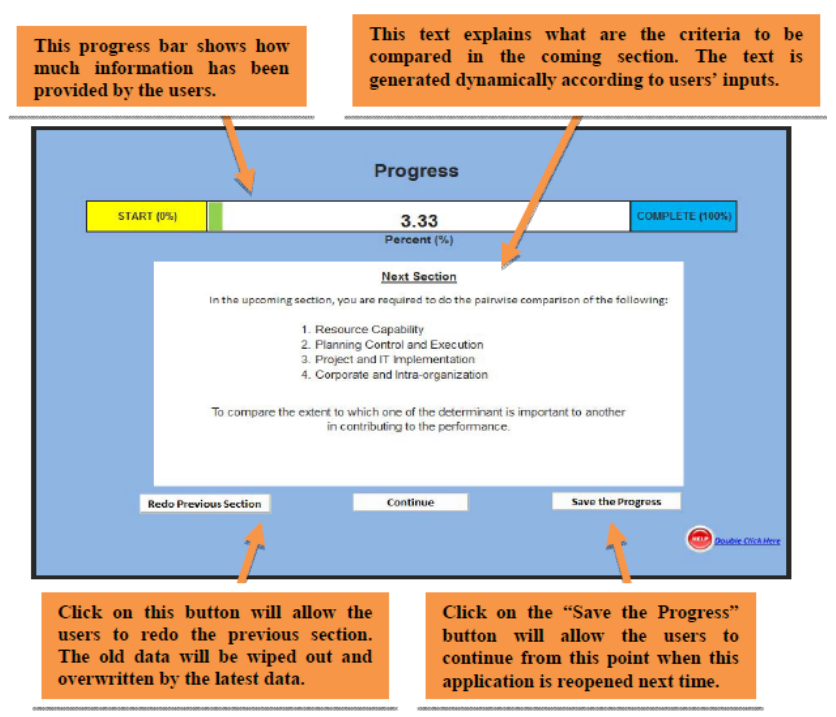

Fig. 4. Progress tracking.

\section{E. Pairwise Comparison Form}

The pairwise comparison is displayed as a pop-up menu to allow the users to still be able to refer to the description of the section and make them well-aware of what are they comparing. For all the pair-wise comparisons, Saaty's (1996) recommendation of using a scale of 1-9 was adopted; 1 implies equal impact while 9 implies stronger impact of one relative to the other. The reciprocal of the number from 1 to 9 is assigned accordingly to the reverse comparison. The colour of the pop-up menu will change for each section, to keep the users aware of the changing of the section. 


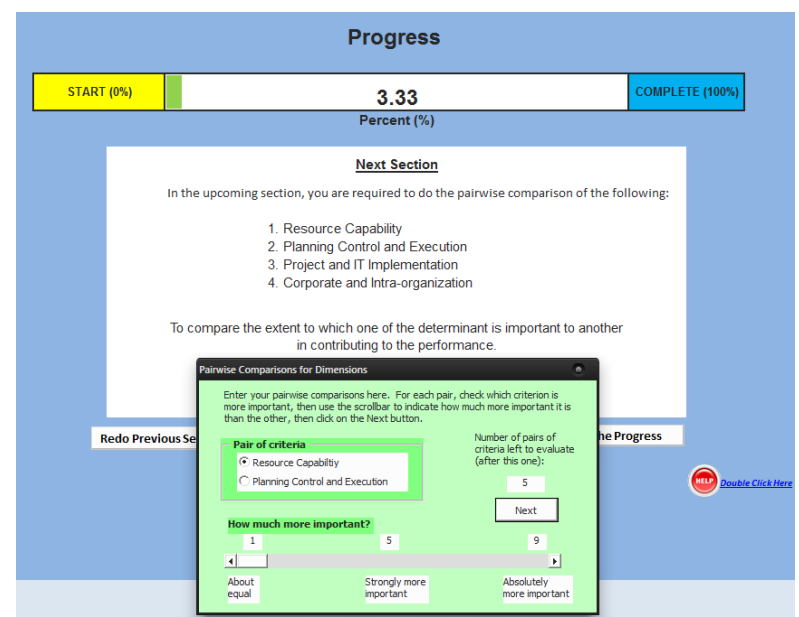

Fig. 5. Pairwise comparison form.

\section{F. View Report}

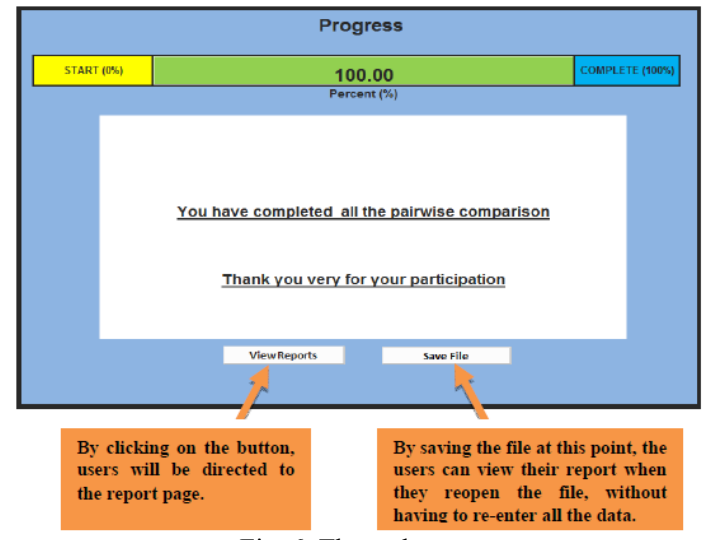

Fig. 6. The end page.

TABLE II: INDEX PERFORMANCE

\begin{tabular}{|c|c|c|c|}
\hline $\begin{array}{l}\text { Month (in } \\
\text { year 2011) }\end{array}$ & $\begin{array}{l}\text { Cases of } \\
\text { employees } \\
\text { dissatisfaction }\end{array}$ & $\begin{array}{l}\text { Unified } \\
\text { Index }\end{array}$ & Improvement \\
\hline Jan & 5 & - & - \\
\hline Feb & 4 & - & - \\
\hline Mac & 3 & - & - \\
\hline Apr & 3 & - & - \\
\hline May & 4 & - & - \\
\hline June & 4 & - & \\
\hline \multicolumn{4}{|l|}{$\begin{array}{l}\text { Index Project } \\
\text { takeoff }\end{array}$} \\
\hline Mid July & 2 & 0.67 & $50 \%$ \\
\hline Aug & 1 & 0.75 & $50 \%$ \\
\hline Sept & 1 & 0.53 & 0 \\
\hline Oct & 0 & 0.43 & $100 \%$ \\
\hline Nov & 1 & 0.62 & * \\
\hline Dec & 0 & 0.65 & $100 \%$ \\
\hline
\end{tabular}

Note ${ }^{1}: 1$ case was reported in Nov due to customer complaint on one of the sub-products.

2: Improvement is calculated as [((value in previous month) - (value in current month)) / (value in previous month)] x $100 \%$.

\section{CASe Study Application}

The computer model was implemented in the case study company. The unified index offer more transparent decision in every department. To see the effectiveness of the model, we compare the number of cases of employees' disagreement

and fire-fighting among the department. The responses were obtained from interviewing the managers. After a period of six months after the computer model was implemented, managers were asked to provide their subjective feedback on how they viewed the effectiveness of the unified index. Most of the managers agree that to a certain extent the index had helped to align the focus. According to them, over the past six months, there was indeed some significant reduction in the number of cases of employees' dissatisfaction. (Note: this is not officially documented in the company as there is no explicit rule to minute down the cases). Nevertheless, the results obtained were unanimously agreed by the managers. They also commented that certain benchmark level need to be taken into consideration to see the improvement level. Table II below showed the number of cases of employees' dissatisfaction and the improvement level after using the unified index. (Note: the decreasing trend of cases reported indicates that satisfaction level increases).

\section{CONCLUSION}

This paper develops a computer model to assess lean performance. The results signified that the model has managed to strengthen the team work in the organization which is an important element in a lean system. For future research, the computer model can be further enhanced with report generation feature to meet the ever increasing demand and requirements of the end user.

\section{ACKNOWLEDGMENT}

The author acknowledge the grant support [1001/PMGT/816191] by the RCMO Universiti Sains Malaysia.

\section{REFERENCES}

[1] G. Fliedner, "Sustainability: A new lean principle," working paper, Decision and Information Sciences Department, School of Business Administration, Oakland University, Rochester, MI. 2008.

[2] D. Mollenkopf, H. Stolze, W. L. Tate, and M. Ueltschy, "Green, lean and global supply chains," International Journal of Physical Distribution and Logistics Management, vol. 40, no. 1-2, pp. 14-41, 2010 .

[3] P. Achanga, V. Taratoukhine, R. Roy, and G. Nelder, "The application of lean manufacturing within small and medium sized enterprises: What are the impediments?" in Proc. 2nd International Conference on Manufacturing Research (ICMR), pp. 143-152, 2004.

[4] V. Mahidhar, "Designing the lean enterprise performance measurement systems," Master thesis. Massachusetts Institute of Technology, 2005.

[5] T. L. Saaty, Decision making with dependence and feedback: The analytic network process, Pittsburgh, PA, RWS Publication, 1996.

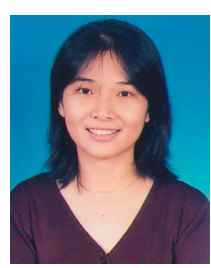

with Application.

Wai Peng Wong is a senior lecturer in operations at School of management, Universiti Sains Malaysia. She obtained her Ph.D in Industrial \& Systems Engineering, NUS. Her research interests include lean, supply chain management and business process management. Her papers have appeared in numerous ISI journals such as IEEE Transactions on Automatic Control, Industrial Management and Data Systems and Expert Systems 